\title{
Non-Nociceptive Environmental Stress Induces Hyperalgesia, Not Analgesia, in Pain and Opioid-Experienced Rats
}

\author{
Cyril Rivat', Emilie Laboureyras', Jean-Paul Laulin ${ }^{1,2}$, Chloé Le Roy', Philippe Richebé ${ }^{1,3}$ and \\ Guy Simonnet*, \\ 'Laboratoire 'Homéostasie-Allostasie-Pathologie', Université Victor Ségalen Bordeaux 2, Bordeaux, France; '2Department of Cellular Biology and \\ Physiology, Université Bordeaux I, Talence, France; ${ }^{3}$ Department of Anesthesia and Intensive Care II, Centre Hospitalier Universitaire de \\ Bordeaux, Bordeaux, France
}

\begin{abstract}
It is well admitted that stress induces analgesia (SIA) via endogenous opioid release. However, there is evidence that stressful events play a role in the pathogenesis of pain, but little is known about mechanisms underlying such pain vulnerability. Previous studies reported that a single opioid exposure activates NMDA-dependent pronociceptive systems leading to long-term pain vulnerability after analgesia. Here, we studied whether prior inflammatory pain or/and opioid experiences may favour the development of pain vulnerability after nonnociceptive environmental stress (NNES). Nociceptive threshold (NT) changes were evaluated by paw pressure vocalization test. By contrast to discrete SIA observed in naive rats, I h stress induced hyperalgesia (SIH) for several hours (I 5-65\% NT decrease) in pain and opioid experienced rats. Repetition of NNES induced an I8- to 22-fold SIH enhancement (3-4 days), whereas SIA decreased. SIH was still observed 4 months after pain and opioid experiences. This phenomenon is referred to as latent pain sensitization. Furthermore, a fentanyl ultra-low dose (ULD, $50 \mathrm{ng} / \mathrm{kg}$ ) administration, mimicking SIA in naive rats, induced hyperalgesia $(65 \% \mathrm{NT}$ decrease, $4 \mathrm{~h}$ ), not analgesia, in pain and opioid-experienced rats. This indicates that low levels of opioids induce opposite effects, that is analgesia vs hyperalgesia dependent on prior life events. In pain and opioid-experienced rats, NMDA receptor antagonists, ketamine or BN2572, completely prevented hyperalgesia when injected just before NNES or fentanyl ULD. This latent pain sensitization model may be important for studying the transition from acute to chronic pain and individual differences in pain vulnerability associated with prior life events.
\end{abstract}

Neuropsychopharmacology (2007) 32, 2217-2228; doi:I0.1038/sj.npp. I 30I340; published online I4 February 2007

Keywords: stress; analgesia; hyperalgesia; opioid; pain sensitization

\section{INTRODUCTION}

Currently, it is well recognized that stress induces analgesia. Among various CNS systems involved in producing stressinduced analgesia (SIA), endogenous opioids play a critical role (Akil et al, 1976; Lewis et al, 1980). However, hyperalgesia following stress has also been reported in animals (Vidal and Jacob, 1982) especially when stress is repeated for a long time (Satoh et al, 1992; da Silva Torres et al, 2003; Bradesi et al, 2005; Khasar et al, 2005; Gameiro et al, 2006). Unlike SIA, the mechanisms involved in stressinduced hyperalgesia (SIH) are poorly understood. Nevertheless, it has been recently reported that long-lasting delayed swim stress-induced thermal hyperalgesia might be prevented by $\mu$-opioid receptor antagonists (Suarez-Roca

\footnotetext{
*Correspondence: Professor G Simonnet, Laboratoire 'HoméostasieAllostasie-Pathologie' EA3666, Université Victor Ségalen-Bordeaux 2, I 46 Rue Leo Saignat, Bordeaux 33076, France, Tel: + 3355757|406, Fax: + 3355757|412, E-mail: gsimonnet@yahoo.com Received 31 July 2006; revised I 9 December 2006; accepted 2 January 2007
}

et al, 2006) suggesting that endogenous opioid systems may paradoxically play a role in SIH.

On the other hand, though it is well demonstrated that exogenous opioids induce analgesia, we previously demonstrated that delayed and long-lasting hyperalgesia appears in a dose-dependent manner after analgesia following single opioid administration in rats (Laulin et al, 1998; Célèrier et al, 2000; Laulin et al, 2002). Consistent with these data, a single opioid administration strongly enhances the longlasting hyperalgesia following inflammation or surgical incision in rats (Rivat et al, 2002; Richebe et al, 2005). In agreement with the pain sensitization hypothesis (Woolf and Salter, 2000), we previously observed that animals that had inflammatory pain experience developed an enhanced hyperalgesia in response to the same tissue injury 1 week later (Rivat et al, 2002). This was particularly evident when they had been treated by a single exposure to a potent opioid, such as fentanyl, to relieve the initial inflammatory pain. This indicates that a single opioid administration facilitated the development of long-term pain vulnerability (Célèrier et al, 2001; Rivat et al, 2002). Interestingly, NMDA receptor antagonists prevent exaggerated hyperalgesia in 
both inflammatory and surgical pain in rats treated by fentanyl (Rivat et al, 2002; Richebe et al, 2005) indicating that NMDA-dependent pronociceptive systems play a critical role in pain sensitization induced by a single exposure to exogenous opioid (Hirbec et al, 2000; Bespalov et al, 2001; Mao, 2002; Ossipov et al, 2003; Simonnet and Rivat, 2003). Similarly, short-term infusion of the $\mu$-opioid receptor agonist remifentanil in human volunteers causes hyperalgesia after analgesia (Angst et al, 2003). Exaggerated hyperalgesia has also been reported in postoperative pain patients treated with opioids for surgery (Stubhaug and Breivik, 1997; Guignard et al, 2000). As observed in animal experimental studies, the administration of the NMDA receptor antagonist ketamine opposes opioid-induced hyperalgesia in humans (Stubhaug and Breivik, 1997; De Kock et al, 2001; Guignard et al, 2002; Angst and Clark, 2006; Wilder-Smith and Arendt-Nielsen, 2006).

As high doses of exogenous opioids paradoxically induce delayed and long-lasting pain sensitization, it is essential to know, from a pathophysiological viewpoint, the effects of endogenous opioids released due to stress on pain sensitivity in animals with prior pain and opioid experiences. As SIA has been always studied in naive animals lacking pain experience, we re-examined the effects of an opioid-dependent stress, that is non-nociceptive environmental stress (NNES), on nociceptive threshold (NT) in rats that had previously lived through inflammatory pain or/and fentanyl experiences. NNES is induced by placing animals for $1 \mathrm{~h}$ in new boxes with fresh litter exposed to a light source. Based on the critical role of NMDA receptor systems in opioid-induced hyperalgesia (Mao et al, 1994; Laulin et al, 1998; Célèrier et al, 2000), we evaluated the effect of two NMDA receptor antagonists, ketamine (Hirota and Lambert, 1996) and BN2572, the gacyclidine enantiomer (-) (Hirbec et al, 2000) on stress-induced changes in pain sensitivity. Finally, we examined long-term pain vulnerability induced by pain and opioid experiences by reexposing animals to NNES several weeks later.

\section{MATERIALS AND METHODS}

\section{Animals}

Experiments were performed on adult male SpragueDawley rats (IFFA-CREDO, L'arbresle, France) weighing 200-225 g, housed in groups of four per cage under a $12 \mathrm{~h}$ light/dark cycle (lights on at 07:00) at a constant room temperature of $23 \pm 2^{\circ} \mathrm{C}$. Food and water were available ad libitum. All experiments were performed during the light period. Pharmacologic tests and care of animals were conducted in accordance with the official edict presented by the French Ministry of Agriculture (Paris, France) and the local ethical committee rules. Accordingly, these experiments were conducted in an authorized laboratory and under the supervision of an authorized researcher (J-PL).

\section{Drugs}

Fentanyl citrate, ketamine hydrochloride, naltrexone, and carrageenan $\lambda$ (Sigma-Aldrich, Saint-Quentin Fallavier, France) were dissolved in normal saline (0.9\%). BN2572, the gacyclidine enantiomer (-)-(1S-2R)-1-[1-(2-thienyl)-2methylcyclohexyl] piperidine was obtained from BEAUFOUR-IPSEN (Les Ulis, France). Fentanyl $(100 \mu \mathrm{g} / \mathrm{kg})$, ketamine $(10 \mathrm{mg} / \mathrm{kg})$, BN2572 $(0.3 \mathrm{mg} / \mathrm{kg})$, and naltrexone $(1 \mathrm{mg} / \mathrm{kg})$ were administered subcutaneously $(1 \mathrm{ml} / \mathrm{kg}$ body weight). Control animals received an equal volume of saline injections. Carrageenan $\lambda(0.2 \mathrm{ml}$ of a $1 \%$ solution of carrageenan in saline) was prepared $24 \mathrm{~h}$ before each experiment.

\section{Nociceptive Testing}

NTs were determined in handled rats by a modification of the Randall-Selitto method (Kayser and Guilbaud, 1990) involving the paw-pressure vocalization test, in which a constantly increasing pressure is applied on the hind paw until the rat squeaks. The Basile analgesimeter (Apelex, Massy, France; stylus tip diameter, $1 \mathrm{~mm}$ ) was used. A 600 -g cutoff value was set to prevent tissue damage. In all experiments, NT was determined on inflamed or noninflamed hind paws.

\section{Inflammatory Pain Model}

The pro-inflammatory compound, carrageenan, was injected into one plantar hind paw subcutaneously (s.c.). Carrageenan injection was performed with a 25-gauge needle.

\section{Opioid Treatment Model}

To mimic a treatment with high doses of opioid as currently used for surgery in humans, fentanyl $(100 \mu \mathrm{g} / \mathrm{kg}$, s.c.) was injected four consecutive times every $15 \mathrm{~min}$ on the experimental day $\left(\mathrm{D}_{0}\right)$, resulting in a total fentanyl dose of $400 \mu \mathrm{g} / \mathrm{kg}$. The first fentanyl injection was performed $5 \mathrm{~min}$ before the carrageenan injection.

\section{Non-Nociceptive Environmental Stress}

NNES is induced by exposing animals for $1 \mathrm{~h}$ to a new environment. Rats were placed in a new experimental room, in new boxes with fresh litter, and were exposed to a light source ( 350 lux) placed at a $2 \mathrm{~m}$ distance from the rat boxes. At the end of the stress session, rats were returned to their home cages in the usual experimental room.

\section{Fentanyl Ultra-Low Dose Test}

In preliminary experiments, we determined the subcutaneous fentanyl dose that induced analgesia similar to analgesia induced by NNES in naive rats. The effective dose is $50 \mathrm{ng} / \mathrm{kg}$. This fentanyl ultra-low dose (ULD) was subcutaneously injected on $\mathrm{D}_{13}$ when the NTs of rats were returned to basal levels.

\section{Experimental Procedure}

After arrival in the laboratory, animals were left to become accustomed to the animal care unit for 4 days. To avoid stress resulting from the experimental conditions that might affect measurement of the NT, the experiments were 
performed by the same experimenter in quiet conditions in a test room close to the animal care unit. For 2 weeks before the experiments, the animals were weighed daily, handled gently for $5 \mathrm{~min}$, and placed in the test room for $2 \mathrm{~h}$ (from 11:00 to 13:00), where they were left to become accustomed to the various apparatuses. All experiments began at 11:00 and were performed on groups of 8-10 animals during the light part of the cycle.

NT measurements were performed on the 2 days preceding the scheduled experimental day (ie on $\mathrm{D}_{-2}$ and $\left.D_{-1}\right)$ and repeated on the experimental day $\left(D_{0}\right)$, just before tissue injury. Experiments were only initiated when no statistical change of the basal pain parameters was observed on three successive days $\left(D_{-2}, D_{-1}\right.$, and $D_{0}$, one-way ANOVA, $p>0.05)$. The reference value of NT was chosen as the basal value on $\mathrm{D}_{0}$.

On $\mathrm{D}_{0}$, NTs were measured 2, 4, $6 \mathrm{~h}$ after carrageenan injection and once daily during the subsequent 13 days. In rats without hind paw inflammation, NTs were similarly measured on $\mathrm{D}_{0}$ and the subsequent 13 days. For the stress period, NT measurements were performed $30 \mathrm{~min}$ after the beginning of each non-nociceptive stress period and every $1 \mathrm{~h}$ for $6 \mathrm{~h}$ during the poststress period. NTs were then estimated once daily until the return to basal NT values. For the fentanyl ULD test, NTs were measured every $30 \mathrm{~min}$ for $4 \mathrm{~h} 30 \mathrm{~min}$.

\section{Experimental Groups}

Four types of experimental groups of rats were used: (i) Naive group: rats received neither high doses of fentanyl on $\mathrm{D}_{0}$ nor pro-inflammatory drug carrageenan in hind paw, (ii) Fentanyl group: rats only received fentanyl (4 boluses of $100 \mu \mathrm{g} / \mathrm{kg}$, s.c.) on $\mathrm{D}_{0}$, (iii) Carrageenan group: rats only received one carrageenan injection in a hind paw on $\mathrm{D}_{0}$, and (iv) Carrageenan-Fentanyl group: rats received both fentanyl injections ( 4 boluses of $100 \mu \mathrm{g} /$ $\mathrm{kg}$, s.c.) and one carrageenan injection in the hind paw on $\mathrm{D}_{0}$.

\section{Experimental Design}

The experimental design of experiments is shown in Figure 1.

First series of experiments. In these experiments, we compared the effects of one NNES on NT in five different experimental groups of rats: two Naive groups, one Fentanyl group, one Carrageenan group, and one CarrageenanFentanyl group. NNES was performed on $\mathrm{D}_{13}$ when rats were returned to the basal NT. In Naive groups, rats received one naltrexone $(1 \mathrm{mg} / \mathrm{kg}$, s.c.) or saline injection, 30 min before the beginning of NNES.

Second series of experiments. In this experiment, we compared the effect of $50 \mathrm{ng} / \mathrm{kg}$ fentanyl on NT in the Naive group $v s$ the Carrageenan-Fentanyl group. This pharmacological test was performed on $\mathrm{D}_{13}$ when the NTs of rats were returned to basal levels.

Third series of experiments. In a first experiment, we compared the effects of three NNES $\left(D_{13}, D_{15}\right.$, and $\left.D_{20}\right)$ on NTs in the Naive group $v s$ the Carrageenan-Fentanyl group. In a second experiment, we evaluated changes in NT induced by NNES in the Carrageenan-Fentanyl group when it was repeated on $\mathrm{D}_{13}, \mathrm{D}_{15}, \mathrm{D}_{20}, \mathrm{D}_{68}$, and $\mathrm{D}_{119}$. In a third experiment, we evaluated the preventive effect of two NMDA receptor antagonists, ketamine or BN2572 (Hirbec et al, 2000), on NT changes in Carrageenan-Fentanyl groups. Rats received either NMDA antagonists or saline as control on $\mathrm{D}_{0}$. In the ketamine group, rats received subcutaneously three $10 \mathrm{mg} / \mathrm{kg}$ ketamine injections, $30 \mathrm{~min}$ before and 4.5 and $9.5 \mathrm{~h}$ after the first fentanyl injection. In the BN2572 group, rats were subject to one BN2572 injection $(0.3 \mathrm{mg} / \mathrm{kg}$, s.c.), $30 \mathrm{~min}$ before the first fentanyl injection. In the BN2572 group, two saline injections were performed 4.5 and $9.5 \mathrm{~h}$ after the first fentanyl injection.

Fourth series of experiments. We evaluated effect of a single administration of the NMDA antagonist BN2572

\section{Experimental Design}

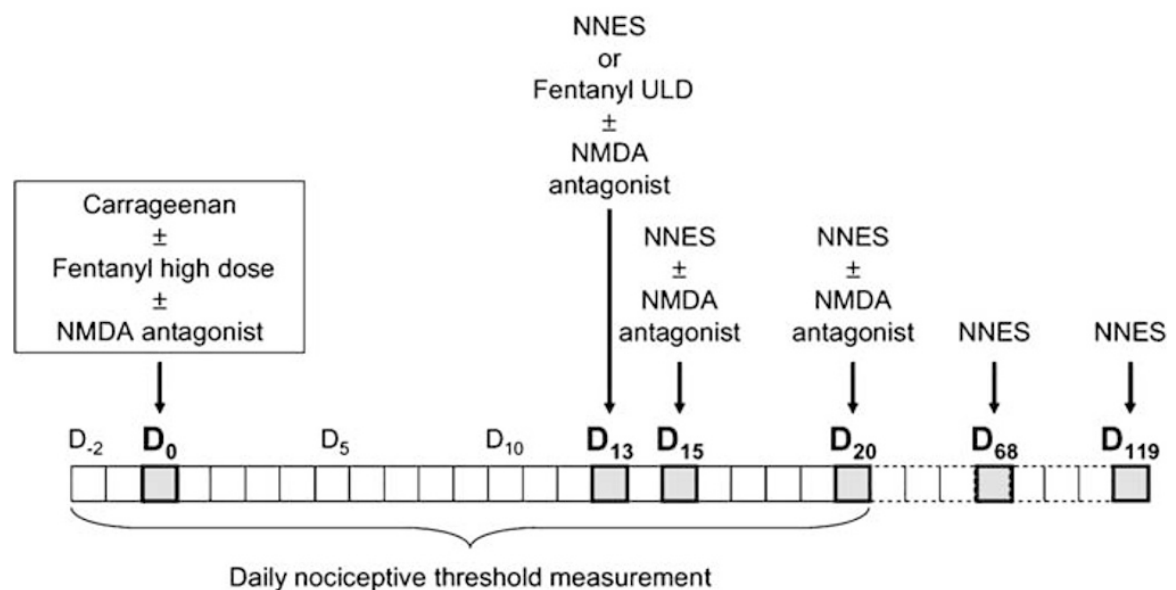

Figure I Experimental design. In rats, NTs were evaluated daily by paw pressure vocalization test. Drugs or saline $(0.9 \% \mathrm{NaCl})$ were administered subcutaneously. The gray squares indicate experimental days with lesion, drug administration, or stress session (see Material and Methods). NNES: Non-nociceptive environmental stress. Fentanyl ULD: fentanyl ultra-low dose. 
$\left(0.3 \mathrm{mg} / \mathrm{kg}\right.$, s.c. on $\left.\mathrm{D}_{13}\right)$ on $\mathrm{NT}$ in Naive groups and Carrageenan-Fentanyl groups in three types of experiments. In the first type of experiment (Control), BN2572 was injected alone. In the second type of experiment (Stress), BN2572 was administered $30 \mathrm{~min}$ before NNES. In the third type of experiment (Fentanyl ULD), BN2572 was administered $30 \mathrm{~min}$ before fentanyl ULD injection.

Fifth series of experiments. In these experiments, the effect of one $\mathrm{BN} 2572$ injection $(0.3 \mathrm{mg} / \mathrm{kg}$, s.c.) or saline just before each stress ( $30 \mathrm{~min}$ before the beginning of NNES) on $D_{13}, D_{15}$, and $D_{20}$ was evaluated in the Naive group and the Carrageenan-Fentanyl group.

\section{Data Analysis}

The data are presented as mean \pm SEM. One-way and twoway ANOVAs were used to assess time effects of treatment on NT (basal reference value: basal value on $\mathrm{D}_{0}$ for all experiments) and individual group comparisons. When a significant effect was observed, post hoc analyses were performed using the Dunnett test. The Newman-Keuls' test was used for multiple comparisons between groups. Analgesic or hyperalgesic indexes represented by the area under or above the curve, respectively, were calculated for each rat by the trapezoidal method and expressed as a mean percentage $( \pm S E M)$ of the reference index (100\%: analgesic or hyperalgesic index associated with analgesia or hyperalgesia observed in the control group). Student's $t$-test was used to evaluate changes in NT induced by naltrexone and for comparison of hyperalgesic index. A difference was considered significant if $p<0.05$.

\section{RESULTS}

\section{NNES Induces Hyperalgesia, not Analgesia, in Pain or/and Opioid-Experienced Rats}

We compared the effects of NNES on naive rats $v s$ rats with previous pain or/and opioid experiences. In naive rats, NNES for a period of $1 \mathrm{~h}$ induced a NT increase (stressinduced analgesia or SIA), which was limited to the stress exposure (Figure $2 \mathrm{a}, p<0.05$ ). When injected $30 \mathrm{~min}$ before the NNES, the opioid receptor antagonist naltrexone prevented the NT increase induced by the stress $(p>0.05)$ indicating that SIA observed in this study was an opioiddependent phenomenon. Conversely, for rats treated with fentanyl 13 days earlier, NNES induced a sustained decrease of the NT (stress-induced hyperalgesia or $\mathrm{SiH}$ ) for $1 \mathrm{~h} 30 \mathrm{~min}$ (Figure 2b, $p<0.05$ ). Similarly, in rats that had recovered their basal NT after inflammatory pain induced by a carrageenan injection performed 13 days earlier, NNES induced a sustained decrease of the NT for $1 \mathrm{~h} 30 \mathrm{~min}$ (Figure $2 \mathrm{c}, p<0.05$ ). In rats that received fentanyl for relieving inflammatory pain, NNES performed 13 days later induced a more significant and sustained decrease of NT as it lasted for $3 \mathrm{~h} 30 \mathrm{~min}$ (Figure 2d, $p<0.05)$.
A Fentanyl ULD Induces Hyperalgesia, not Analgesia, in Pain or/and Opioid-Experienced Rats

To study paradoxical hyperalgesia induced by opioiddependent stress, we determined the dose of an exogenous opioid as fentanyl that mimics the analgesia induced by NNES in naive rats (Naive group). Preliminary studies with various fentanyl doses $(500 \mathrm{pg} / \mathrm{kg}$ to $5 \mu \mathrm{g} / \mathrm{kg}$ ) were performed in naive rats (data not shown). Results show that $50 \mathrm{ng} / \mathrm{kg}$ was the most effective fentanyl dose to mimic SIA (Figure 3a). By contrast, this fentanyl ULD induced a sustained decrease in NT for $4 \mathrm{~h}$ in rats that had experienced pain and were injected with fentanyl 13 days earlier (CarraFenta group). Interestingly, this sustained decrease was also observed for $3 \mathrm{~h} 30 \mathrm{~min}$ (Figure $3 \mathrm{~b}, p<0.05$ ) at the contralateral hind paw level (non-inflamed hind paw). In pain and opioid-experienced rats, basal NT $(260 \pm 11.7 \mathrm{~g})$ did not change $30 \mathrm{~min}$ and $1 \mathrm{~h}$ after saline injection $(253.1 \pm 12.3$ and $255 \pm 13.2 \mathrm{~g}$, respectively).

\section{Repetition of NNES Enhances SIH in Pain and Opioid-Experienced Rats}

In naive rats (Naive group), the SIA amplitude decreased after the second NNES and was strongly reduced following the third NNES (Figures $4 a$ and $b, p<0.05$ ). In pain and opioid-experienced rats (Carra-Fenta group), the repetition of NNES exposure induced a large enhancement of SIH, as a decrease in NT was observed for 3 days after the second and third stress periods (Figure 4c, $p<0.05$ ). Comparison of hyperalgesic indexes showed that $\mathrm{SIH}$ was increased 18- to 22-fold for the second and third stress, respectively, as compared to the first one (Figure $4 \mathrm{~d}$, $p<0.05)$.

\section{A Single Exposure to NMDA Receptor Antagonists on $D_{0}$ Prevents Long-Lasting Hyperalgesia in Pain and Opioid-Experienced Rats and Opposes SIH}

As previously reported, when injected three times at $5 \mathrm{~h}$ intervals on $\mathrm{D}_{0}$, ketamine $(10 \mathrm{mg} / \mathrm{kg}$, s.c.) strongly reduced the long-lasting hyperalgesia induced by the carrageenan injection in fentanyl-treated rats. Indeed, long-lasting hyperalgesia was reduced to 5 days in ketamine-treated rats (Figure 5a, $p<0.05$ ) vs 10 days in non-ketamine-treated rats $(p<0.05)$. A single $\mathrm{BN} 2572$ injection $(0.3 \mathrm{mg} / \mathrm{kg}$, s.c. $)$ performed $30 \mathrm{~min}$ before the carrageenan injection on $\mathrm{D}_{0}$ totally prevented the long-lasting hyperalgesia induced by the carrageenan injection in fentanyl-treated rats (Figure $5 c, p<0.05$ ). Furthermore, the $\mathrm{D}_{0}$ ketamine injections totally prevented SIH when NNES was performed 13 days later (Figures $5 \mathrm{a}$ and $\mathrm{b}, p<0.05$ ). A moderate ketamine preventive effect on SIH was still observed after the second stress exposure. No preventive effect of ketamine was observed after the third stress exposure. Similarly, no SIH was observed in BN2572-treated rats after the first stress exposure (Figures $5 c$ and $d, p>0.05$ ). A significant reduction of second $\mathrm{SIH}$ was still observed in BN2572-treated rats (Figure $5 c, p<0.05$ ). No preventive effect was observed with the third stress exposure. 

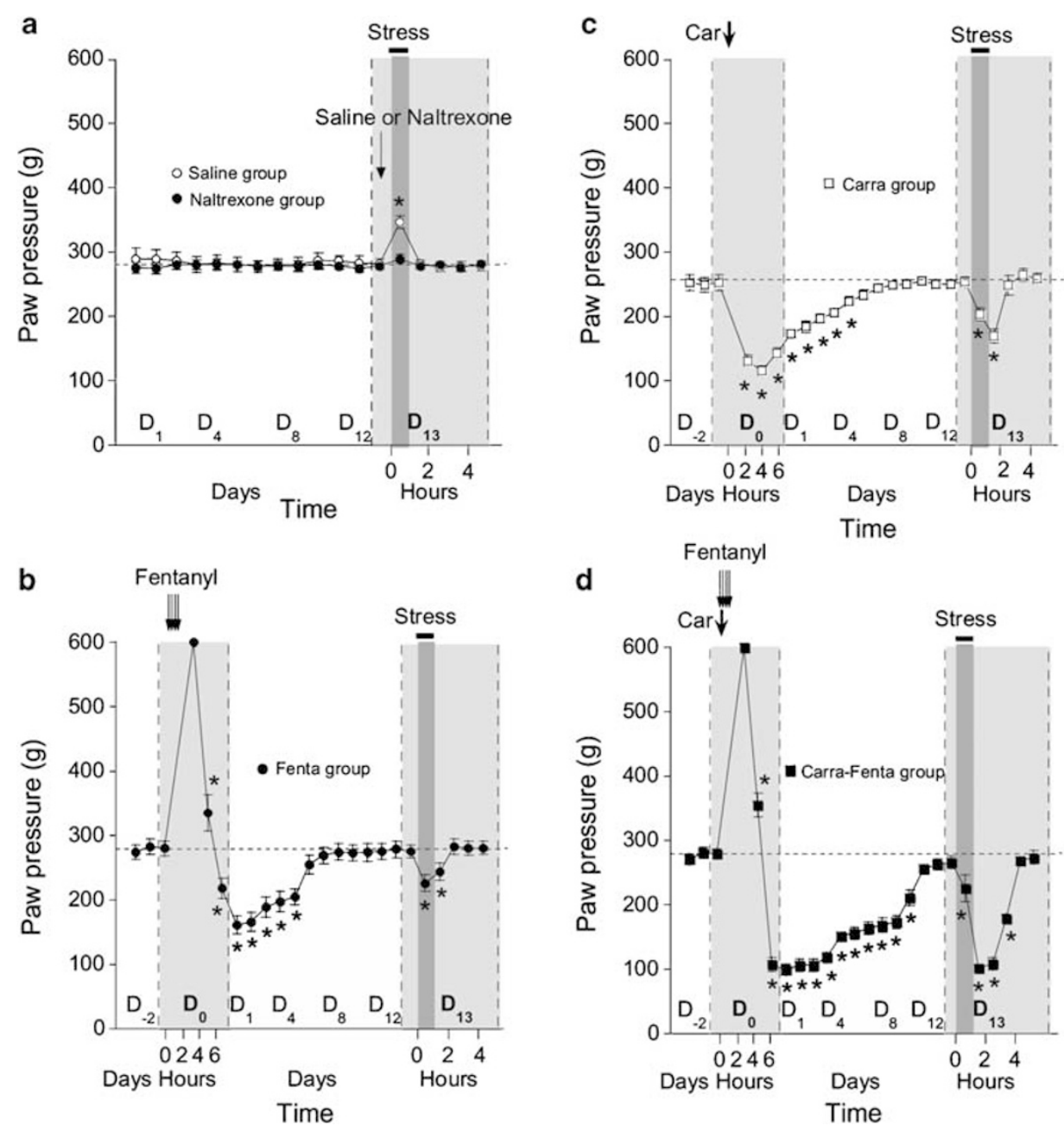

Figure 2 Effect of an NNES on NT in naive and pain or/and opioid-experienced rats. NT changes were evaluated by the paw pressure vocalization test. (a) In naive rats, Naltrexone (I mg/kg, s.c., Naltrexone group $\mathbf{0}$ ) or saline (Saline group $\bigcirc$ ) was injected 30 min before NNES was performed on D 13 . (b) In rats with fentanyl exposure on $D_{0}$ (Fenta group - ) NNES was performed on $D_{13}$ when rats were returned to the basal NTs. (c) In rats with inflammatory pain induced by an intraplantar carrageenan injection on $D_{0}$ (Carra group $\square$ ), NNES was performed on $D_{13}$ when rats were returned to their basal NT. (d) In rats with pain and fentanyl exposure on $D_{0}$ (Carra-Fenta group $\mathbf{a}$ ), NNES was performed on $D_{13}$ when rats were returned to the basal NT. Mean pressure values to trigger vocalization were expressed in grams \pm SEM. * Dunnett test, $p<0.05$ compared with the $D_{0}$ basal NT value. Car: carrageenan, Fenta: fentanyl, Carra-Fenta: Carrageenan-Fentanyl.

\section{Hyperalgesia Induced by NNES or Fentanyl ULD is NMDA-Dependent}

To determine the mechanisms of SIH, we evaluated the effects of NMDA receptor antagonists. When injected alone on $\mathrm{D}_{13}, \mathrm{BN} 2572$ had no effect on both naive and pain and opioid-experienced rats (Figures $6 \mathrm{a}$ and $\mathrm{d}$ ). In naive rats, the administration of BN2572 just before the first NNES or a fentanyl ULD on $D_{13}$ had no effect on SIA or analgesia induced by the fentanyl ULD (Figures $6 \mathrm{~b}$ and $c, p>0.05$ ). Conversely, in pain and opioid-experienced rats, BN2572 totally prevented hyperalgesia induced by the first NNES or a fentanyl ULD (Figures 6e and $\mathrm{f}, p<0.05$ ).

When NNES was repeated two times after the first one, the BN2572 injection just before each NNES $\left(D_{15}\right.$ and $\left.D_{20}\right)$ totally opposed the decrease of SIA observed following the second and third NNES in naive rats (Figures $7 a$ and $b$, $p>0.05)$. In pain and opioid-experienced rats, BN2572 administration totally prevented SIH observed for several days following the second and third NNES (Figures 7c and $\mathrm{d}, p<0.05$ ).

\section{Persistence of SIH in Pain and Opioid-Experienced Rats}

When NNES was repeated 68 and 119 days after pain and opioid experiences, NNES still induced hyperalgesia as indicated by high values of hyperalgesic indexes (Table 1).

\section{DISCUSSION}

Our study confirms that a single exposure to a high dose of opioid strongly enhanced and extended hyperalgesia induced by inflammatory pain via NMDA-dependent pronociceptive systems (Rivat et al, 2002; Richebe et al, 2005). This is in agreement with previous data showing that 


\section{Inflamed hind paw}
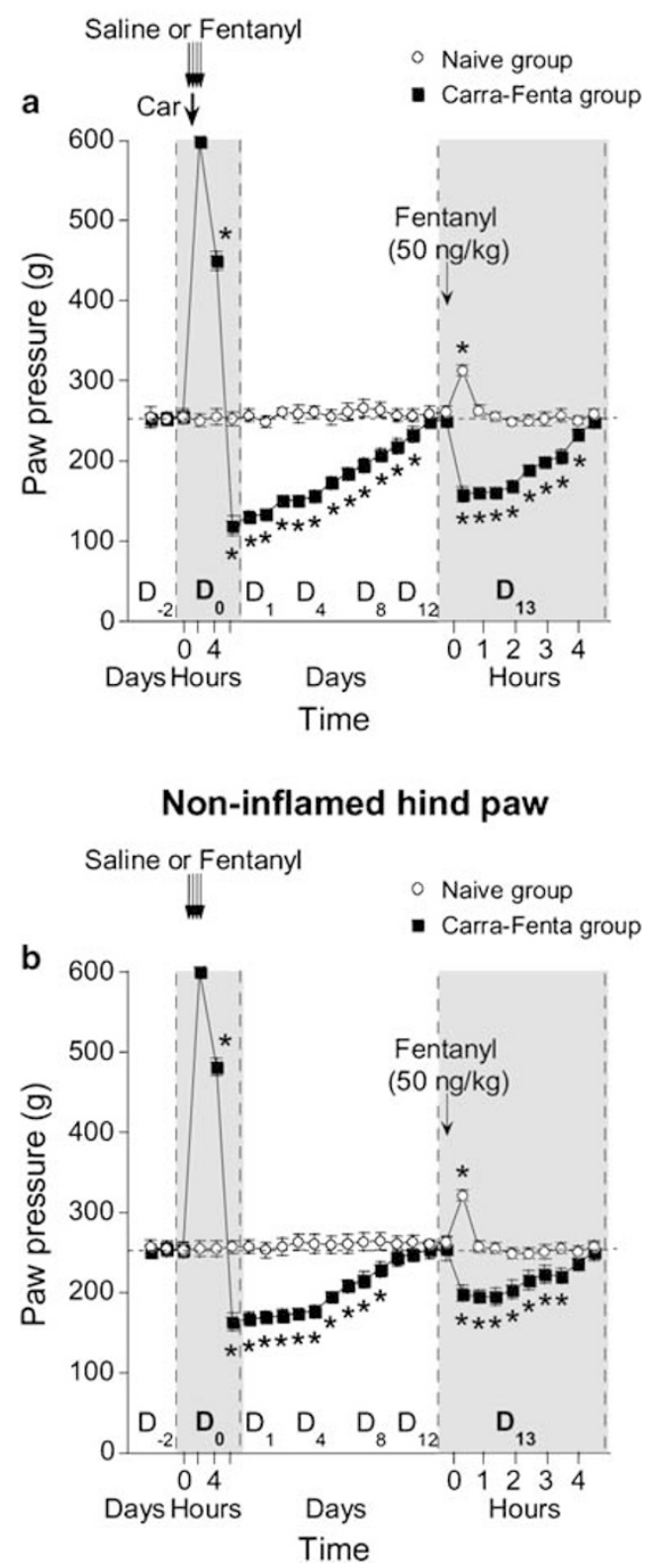

Figure 3 Effect of a fentanyl ULD on NT in naive (Naive group $O$ ) and pain and opioid-experienced rats (Carra-Fenta group $\mathbf{\square}$ ). NT changes were evaluated by the paw pressure vocalization test in both inflamed (a) and non-inflamed (b) hind paws. Fentanyl ULD (50 ng/kg, s.c.) was injected on $D_{13}$. Mean pressure values to trigger vocalization were expressed in grams \pm SEM. * Dunnett test, $p<0.05$ compared with the $D_{0}$ basal NT value. Car: Carrageenan; Carra-Fenta: Carrageenan-Fentanyl. Fentanyl ULD: fentanyl ultra-low dose.

$\mu$-opioid receptor stimulation triggers the activation of NMDA receptors by reducing the $\mathrm{Mg}^{2+}$ block via intracellular protein kinase C activation (Chen and Huang, 1991, 1992). Moreover, morphine induces glutamate transporter downregulation at spinal cord level (Mao et al, 2002). These preclinical results are consistent with clinical data reporting that major surgeries with opioid based anesthesia are associated with exaggerated post-operative pain in humans (Chia et al, 1999; Zarate et al, 1999; Guignard et al, 2000, 2002; Angst and Clark, 2006; Wilder-Smith and Arendt-
Nielsen, 2006). Indeed, accumulative evidence suggests that opioid therapy used to relieve pain, especially surgical pain, may make patients more sensitive to pain and potentially worsen their pre-existing pain (Angst and Clark, 2006; Wilder-Smith and Arendt-Nielsen, 2006).

Based on these data, an interesting pathophysiological question is whether the release of endogenous opioids induced by stress may facilitate or oppose pain vulnerability observed in rats with prior pain and opioid experiences. For this purpose, we developed an NNES consisting in environmental changes, which may affect normal daily activities of wild rats as new environment and lighting enhancement. As expected, a first NNES exposure in naive rats induced a moderate and limited analgesia (SIA), which is totally prevented by a prior naltrexone administration, pointing out its endogenous opioid nature. In contrast, a first NNES exposure in rats with basal NTs after prior pain or fentanyl experiences 2 weeks earlier induced hyperalgesia, but never analgesia. Moreover, SIH observed in painexperienced rats was strongly enhanced in rats that received fentanyl to relieve pain on the carrageenan injection day. Because such SIH was observed in rats that were returned to basal pain sensitivity (normal NT), we named this phenomenon 'latent pain sensitization'. It is consistent with previous data showing that pain and opioid-experienced rats show exaggerated hyperalgesia in response to tissue injury (Rivat et al, 2002). Such pain hypersensitivity is of central origin because SIH was also observed on the contralateral hind paw, which has never been inflamed (data not shown and Rivat et al, 2002). These results demonstrate that NNES induced opposite effects on pain sensitivity dependent on pain and opioid experiences.

Although SIA in naive rats is associated with endogenous opioid release, one question is to know whether endogenous opioid release is also caused by NNES in pain and opioidexperienced rats. Unfortunately, it is not possible to characterize endogenous opioid release by the naloxone test in pain and opioid-experienced rats as it was performed in naive rats, because we (Célèrier et al, 2001; Laulin et al, 2002; Richebe et al, 2005) and others (Martin et al, 1987; Kim et al, 1990) previously reported that naloxone administration precipitated hyperalgesia in these animals. According to these data, we previously suggested that animals with previous pain or/and opioid histories did not return to their initial equilibrium (homeostasis) between opioid-dependent antinociceptive systems and pronociceptive systems. Rather, they were in a new equilibrium (allostasis) with a high level balance between these two opposite pain-controlling systems that mask one another (Célèrier et al, 2001; Simonin et al, 2006). By sharply blocking opioid-dependent antinociceptive systems, naloxone would unmask a high level of pronociceptive system functioning in pain and opioid-experienced rats. For circumventing the methodological difficulty associated with the use of the naloxone test, we decided to investigate in pain and opioid-experienced rats, the effect of an exogenous opioid dose (fentanyl, $50 \mathrm{ng} / \mathrm{kg}$ ) able to mimic the discrete analgesia induced by NNES in naive rats. Indeed, such a fentanyl ULD did not induce analgesia in pain and opioidexperienced rats but caused an opposite response, that is hyperalgesia, for $4 \mathrm{~h}$ as it was observed following NNES. In agreement with SIH observed on the contra lateral hind 

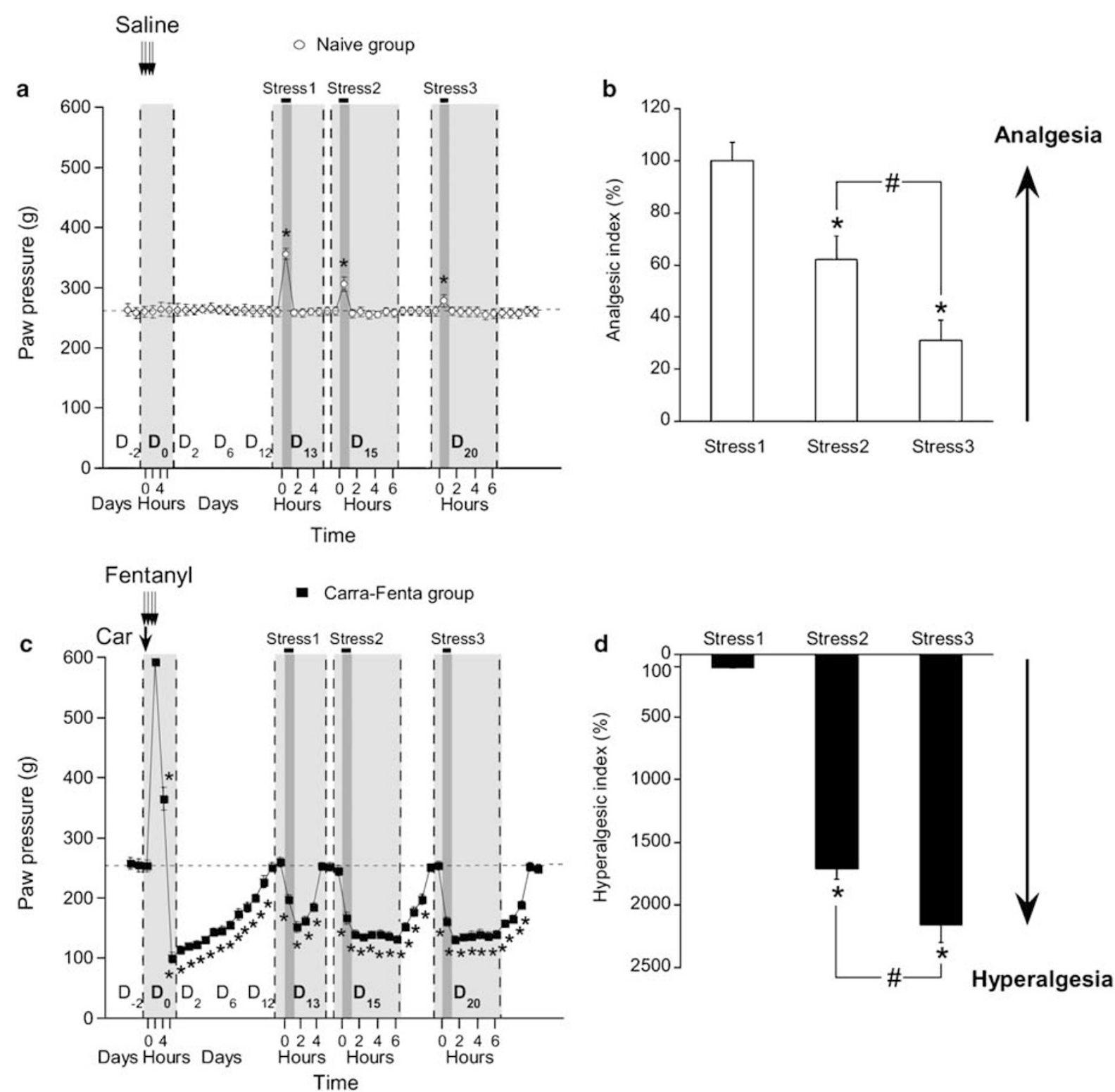

Figure 4 Effect of the repeated NNES on NT in naive (Naive group $O$ ) and pain and opioid-experienced rats (Carra-Fenta group $\mathbf{\square}$ ). NT changes were evaluated by the paw pressure vocalization test. $(a, c)$ NNES were performed on $D_{13}, D_{15}$, and $D_{20}$. Mean pressure values to trigger vocalization were expressed in grams \pm SEM. *Dunnett test, $p<0.05$ compared with the $D_{0}$ basal NT value. (b, d) The algesic indexes were calculated (see Material and Methods) using the variations of the NT of the first, second, and third stress in Naive group (white square) and Carra-Fenta group (black square). *Dunnett test, $p<0.05$ compared with the first stress index and "Dunnett test, $p<0.05$ for comparison between index associated with the second and third stress. Car: Carrageenan; Carra-Fenta: Carrageenan-Fentanyl.

paw, fentanyl ULD also induced hyperalgesia on the noninflamed hind paw confirming the central origin of hyperalgesia. From a pharmacological viewpoint, this is the first demonstration that the same dose of the same compound, that is an opioid as fentanyl, induces two opposite effects, analgesia $v s$ hyperalgesia, dependently on prior life events. Therefore, although endogenous opioid release was not directly estimated in the present study, these results strongly suggest that $\mathrm{SIH}$, as SIA, is also supported by an endogenous opioid release.

From a pathophysiological viewpoint, such pain vulnerability subsequent to pain and opioid histories might have serious outcomes because persistence of nervous system sensitization is now considered a major candidate for the development of chronic pain (Perkins and Kehlet, 2000; Woolf and Salter, 2000). To study this point, we evaluated long-lasting changes in pain sensitivity by repeating NNES for three times in both naive and pain and opioidexperienced rats. Our study showed that the second and third NNES performed few days after the first NNES did not induce a progressive SIH decrease in pain and opioidexperienced rats as this was observed for SIA in naive rats, but conversely induced a rapid and dramatic enhancement of SIH. Indeed, SIH was increased by 18-fold and lasted 3-4 days after the second NNES as compared to $3 \mathrm{~h}$ following the first one indicating a sustained enhancement of pain 

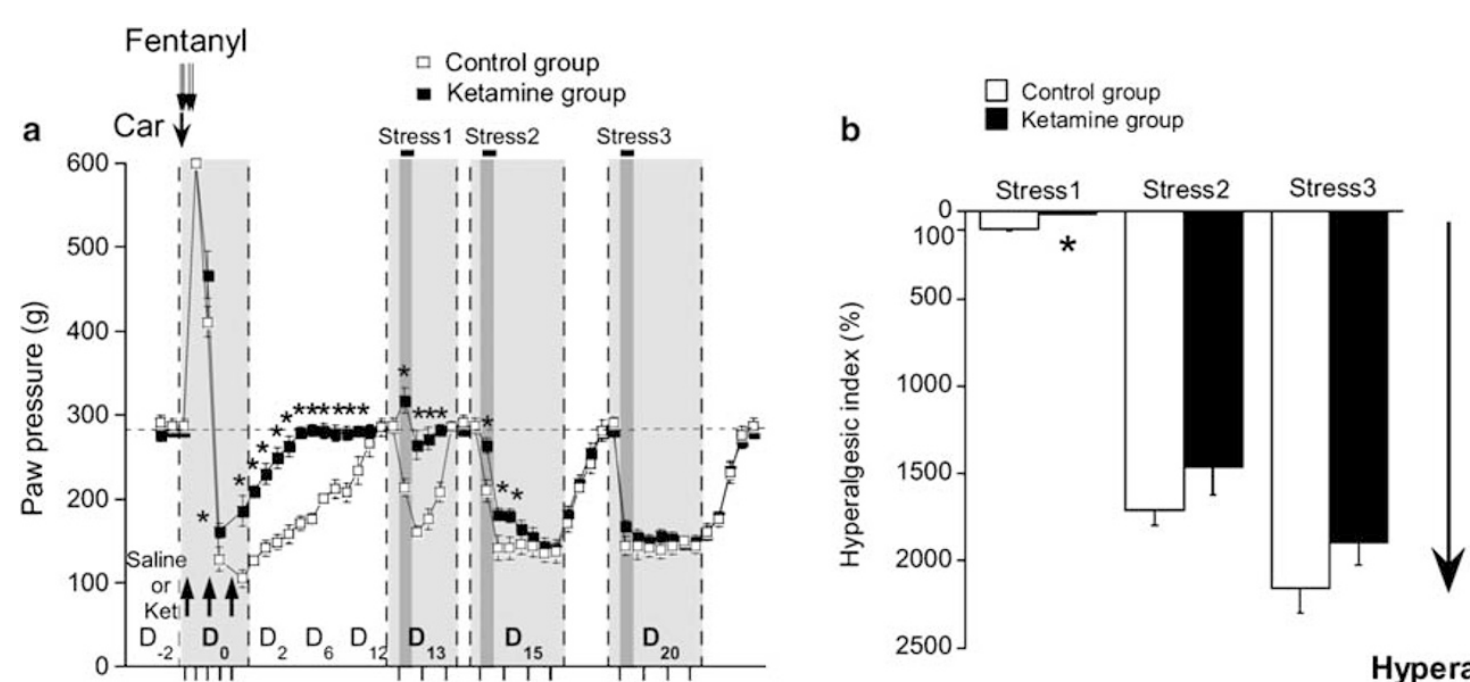

2500

\section{Hyperalgesia}
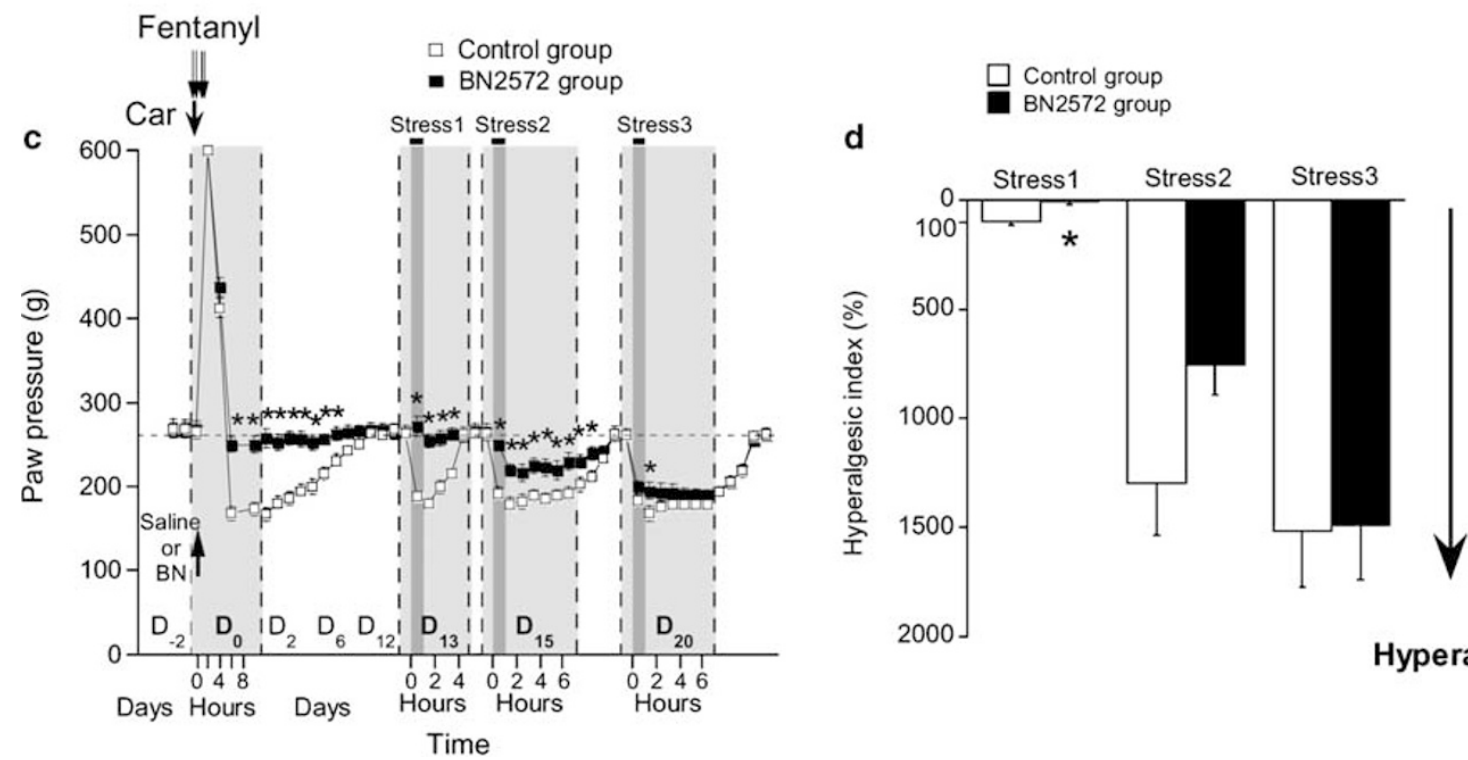

2000

\section{Hyperalgesia}

Figure 5 Preventive effects of NMDA antagonists ketamine and BN2572 administration on NT changes induced by NNES in pain and opioidexperienced rats. NT changes were evaluated by the paw pressure vocalization test. (a) On $\mathrm{D}_{0}$, three boluses of ketamine (I 0 mg/kg, s.c., Ketamine group - ) or saline (Control group $\square$ ) were injected in pain and opioid-experienced rats. NNES were performed on $D_{13}$, $D_{15}$, and $D_{20}$. (c) On $D_{0}$, one bolus of BN2572 $(0.3 \mathrm{mg} / \mathrm{kg}$, s.c., BN2572 group $\mathbf{\square})$ or saline (Control group $\square$ ) was injected in pain and opioid-experienced rats. NNES were performed on D।3, $D_{15}$, and $D_{20}$. Mean pressure values to trigger vocalization were expressed in grams $\pm S E M$. *Newman-Keuls' test, $p<0.05$ for comparison between groups. (b, d) The hyperalgesic indexes were calculated (see Material and Methods) using the variations of the NT of the first, second, and third stress in Control group (white square) and Ketamine or BN2572 group (black square). *Newman-Keuls' test, $p<0.05$ for comparison between groups. Car: Carrageenan; Ket: ketamine; BN: BN2572.

hypersensitivity. In agreement with the sustained overbalance from analgesia to hyperalgesia in response to low levels of opioids, we also observed that NNES performed 68 and 119 days after initial pain and opioid experiences still induced hyperalgesia, but never analgesia. Finally, this suggests that low levels of endogenous opioids released by NNES may paradoxically make animals more sensitive to nociceptive inputs and potentially worsen their pre-existing pain.

As opioids are well-known to induce analgesia, but not hyperalgesia, the hyperalgesia induced by a fentanyl ULD or NNES in pain and opioid-experienced rats are unexpected and paradoxical when viewed from the standpoint of traditional opioid pharmacology concepts. From a mechan- istic viewpoint, it is well recognized that $\mathrm{Gi} / \mathrm{G}_{0}$-coupled inhibitory effects mediated by opioid receptors provide a useful cellular model of opioid analgesia (North and Williams, 1976). By contrast, there is consonance of multidisciplinary experimental evidence that ULDs of morphine may induce hyperalgesia in rats via the recruitment of Gs-coupled excitatory opioid receptor (Crain and Shen, 1990). Interestingly, in vitro studies have shown that opioid exposure may rapidly switch opioid receptor coupling from $G_{i} / G_{0}$ to $G s$, thereby converting these receptors from an inhibitory to excitatory mode (Crain and Shen, 1998) leading to a supersensitized excitatory opioid receptor function. On the other hand, a very recent study has reported that hyperalgesia induced by low 
Control
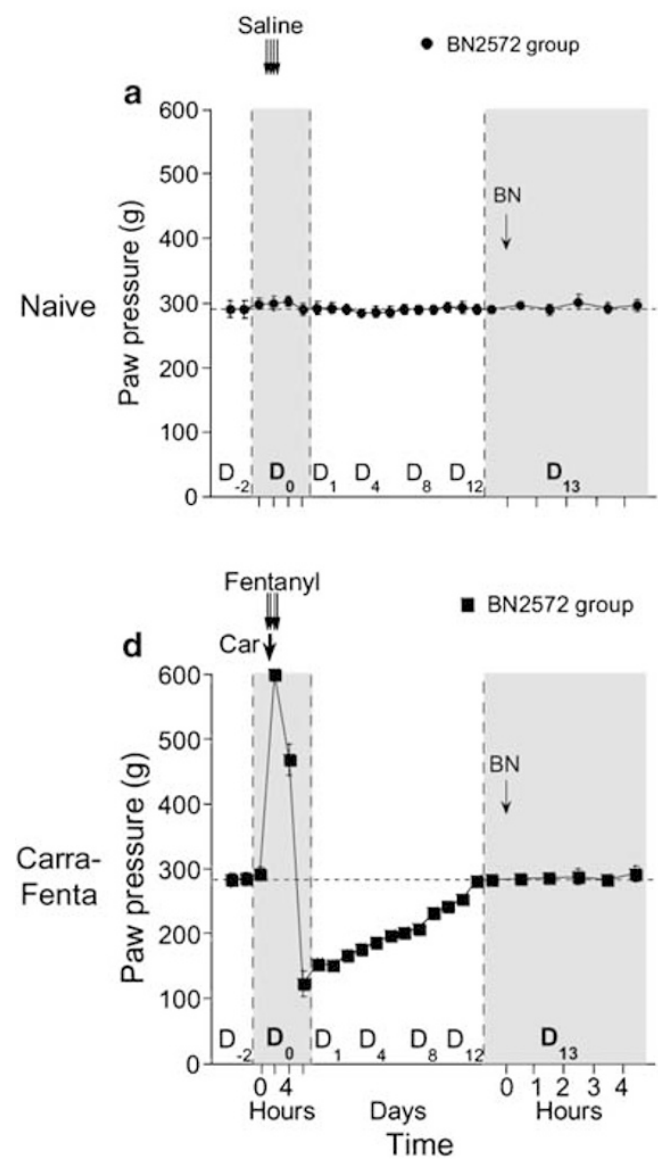

Stress
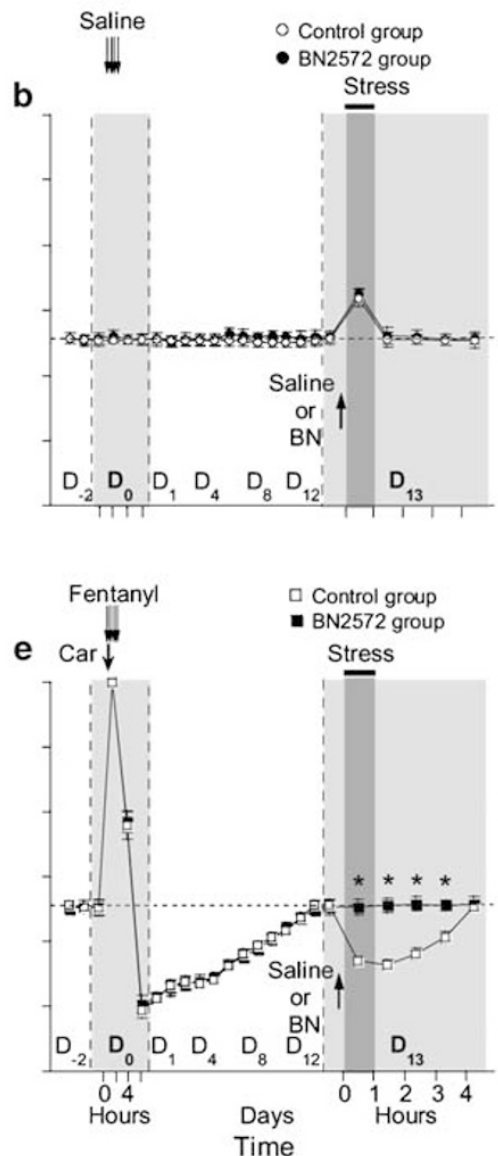

Fentanyl ULD
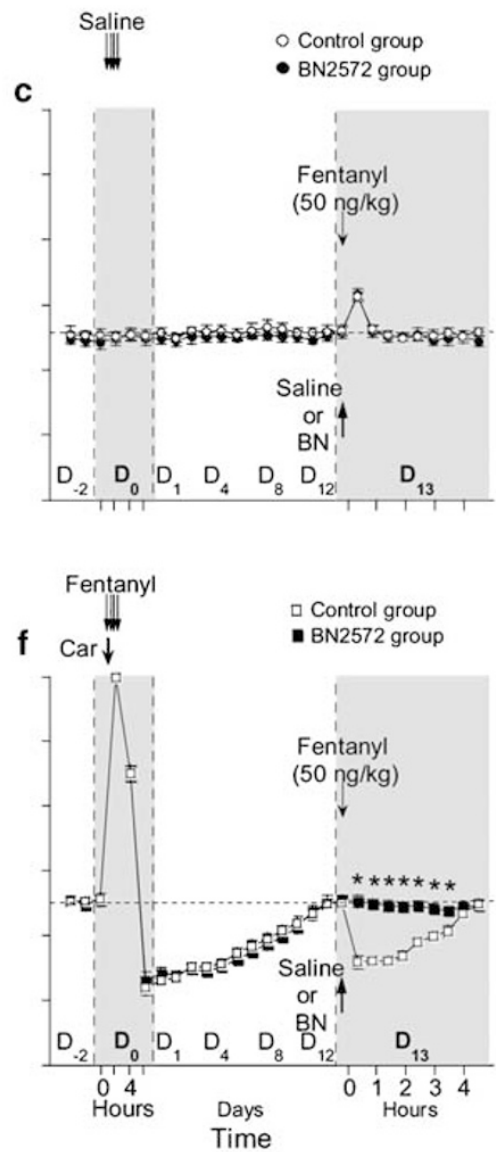

Figure 6 Effects of the NMDA receptor antagonist BN2572 administration just before NNES or fentanyl ultra-low dose (ULD) on NT changes. NT changes were evaluated by the paw pressure vocalization test. (a) In Naive group (O), rats were injected with BN2572 (0.3 mg/kg, s.c.) on D 13. (b, c) On $D_{13}, B N 2572(0.3 \mathrm{mg} / \mathrm{kg}, \mathrm{BN} 2572$ group 0 ) or saline (Control group $\mathrm{O}$ ) was subcutaneously injected in naive rats (Naive) 30 min before NNES or fentanyl ULD (50 ng/kg, s.c.). (d) In Carra-Fenta group ( $)$, rats were injected with BN2572 (0.3 mg/kg, s.c.) on D 13. (e, f) On D 13, BN2572 (0.3 mg/kg, BN2572 group $\mathbf{\square}$ ) or saline (Control group $\square$ ) was subcutaneously injected in pain and opioid-experienced rats (Carra-Fenta) 30 min before NNES or fentanyl ULD (50 ng/kg, s.c.). Mean pressure values to trigger vocalization were expressed in grams \pm SEM. *Newman-Keuls' test, $p<0.05$ for comparison between groups. Car: Carrageenan; Carra-Fenta: Carrageenan-Fentanyl; BN: BN2572. Fentanyl ULD: fentanyl ultra-low dose.

morphine doses involve a PLC $\beta 3 / \mathrm{PKC} \gamma / \mathrm{NMDA}$ pathway, which can be reversed by NMDA receptor antagonists (Galeotti et al, 2006). Similarly, it has been reported that sustained thermal hyperalgesia, not analgesia, is observed following a series of three swim stress episodes in rats (Suarez-Roca et al, 2006). This last study indicates such SIH is prevented by $\mu_{1}$ receptor antagonists indicating that the induction of $\mathrm{SIH}$ is opioid-dependent in nature. Interestingly, this study also shows the involvement of NMDA receptors in both the initiation and maintenance of this phenomenon. In this respect, several observations of our study are able to reveal some mechanisms supporting the overbalance from analgesia to hyperalgesia induced by stress or fentanyl ULD in pain and opioid-experienced rats.

The first observation is that a single NMDA receptor antagonist administration associated with the initial high fentanyl dose and pain experiences totally prevented hyperalgesia induced by the first NNES 2 weeks later. However, this preventive effect was strongly reduced for the second NNES and totally disappeared following the third
NNES. Interestingly, the most potent NMDA receptor antagonist for reducing long-lasting hyperalgesia, BN2572, was also the most potent for preventing $\mathrm{SIH}$ following the second NNES. By contrast, the second observation is that the administration of the NMDA receptor antagonist BN2572 just before NNES or fentanyl ULD administration totally prevented hyperalgesia in rats with prior pain and fentanyl experiences. This means that a sustained NMDA receptor blockade is required for opposing the latent overactivation of NMDA-dependent pronociceptive sytems induced by NNES in pain and opioid-experienced rats. As a whole, this suggests that the pain vulnerability observed in these animals, as revealed by hyperalgesia, was not paradoxically associated with an excess of basal NMDAdependent pronociceptive functioning but is due to a new activation of NMDA-dependent pronociceptive systems requiring opioid receptor stimulation by exogenous or endogenous opioids. The third observation is that NMDA receptor antagonist administration in pain and opioidexperienced rats had no analgesic effect per se in rats that 

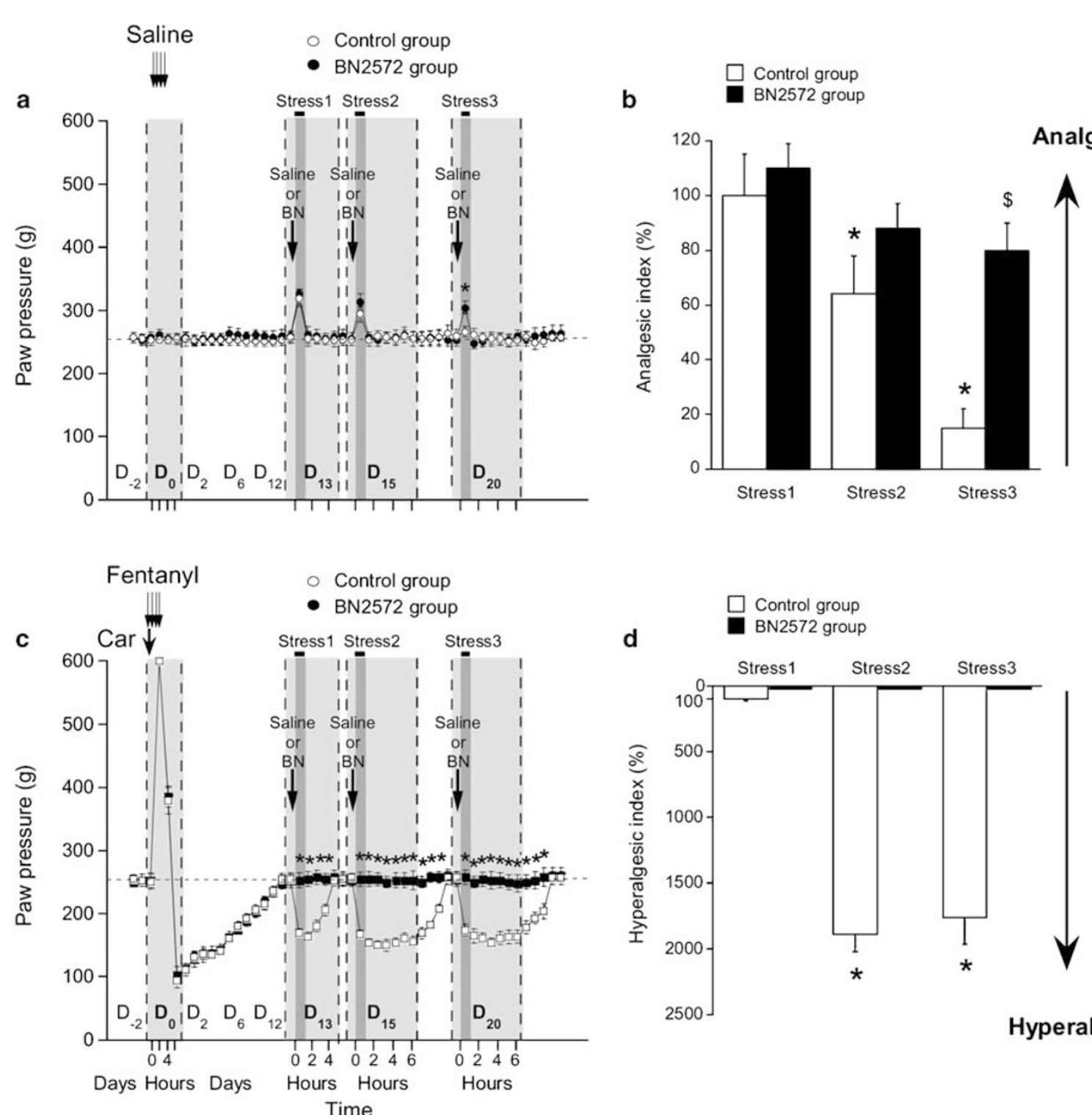

Hyperalgesia

Figure 7 Effects of the NMDA receptor antagonist BN2572 administration just before repeated NNES on NT changes. NT changes were evaluated by the paw pressure vocalization test. (a) In naive rats, BN2572 (0.3 mg/kg, s.c., BN2572 group O) or saline (Control group 0 ) was injected 30 min before each NNES was performed on $D_{13}, D_{15}$ and $D_{20}$. (c) In pain and opioid-experienced rats, BN2572 (0.3 mg/kg, s.c., BN2572 group $\left.\mathbf{\square}\right)$ or saline (Control group $\square$ ) was injected 30 min before each NNES performed on $D_{13}, D_{15}$, and $D_{20}$. Mean pressure values to trigger vocalization were expressed in grams \pm SEM. *Newman-Keuls' test, $p<0.05$ for comparison between groups. (b, $d$ ) In naive rats and pain and opioid-experienced rats, the algesic indexes were calculated (see Material and Methods) using the variations of the NT of the first, second, and third stress in Control group (white square) and BN2572 group (black square). * Dunnett test, $p<0.05$ compared with the first stress index and ${ }^{\$}$ Newman-Keuls' test, $p<0.05$ for comparison between groups. Car: Carrageenan; BN: BN2572.

Table I Changes in Hyperalgesic Indexes Associated with Stress-Induced Hyperalgesia Following NNES Performed on $D_{13}, D_{15}, D_{20}, D_{68}$, and $D_{1 / 9}$ in Pain and Opioid-Experienced Rats

\begin{tabular}{|c|c|c|c|c|c|}
\hline Stress & $D_{13}$ (Ist stress) & $D_{15}$ (2nd stress) & $D_{20}$ (3rd stress) & $D_{68}$ (4th stress) & $D_{119}$ (5th stress) \\
\hline
\end{tabular}

$\mathrm{HI}$ is the mean percentage \pm SEM of the reference hyperalgesic index (I00\%: hyperalgesic index associated with hyperalgesia observed following the first NNES). *Dunnett test, $p<0.05$ compared with $\mathrm{HI}$ associated with the first NNES. HI: hyperalgesic index.

were returned to basal NTs, suggesting that reduction of hyperalgesia induced by NNES or fentanyl ULD was not due to an analgesic effect masking hyperalgesia. The fourth observation showed that an NMDA receptor antagonist administration did not affect analgesia induced by a first NNES or a fentanyl ULD in naive rats. However, it 
prevented the gradual analgesia decrease observed in naive rats following repeated stress, suggesting that reduction of analgesia could be associated with a progressive activation of NMDA-dependent pronociceptive systems by repeated opioid receptor stimulation. The fifth observation is that the 18 -fold enhancement of SIH following the second NNES was totally preventable by a single NMDA receptor antagonist administration performed just before NNES. Indeed, the pharmacological effect of BN2572 lasted for several days outlasting the half-life of this compound (Hoizey et al, 2001). Therefore, an NMDA receptor system mainly appears as a trigger to induce long-lasting activation of pronociceptive systems leading to sustained hyperalgesia. This suggests that pronociceptive systems other than NMDA receptor systems are involved in the long-term expression of SIH. Anti-opioid peptides, such as dynorphin, cholecystokinin, and neuropeptide FF might be good candidates because they have been reported to be involved in opioidinduced hyperalgesia (Vanderah et al, 2000; Xie et al, 2005; Simonin et al, 2006). Studies are in progress to evaluate the role of such endogenous anti-opioid systems in the development of pain vulnerability observed in rats following pain and opioid experiences as reported in this study.

Finally, although it is difficult to think that the same compound, that is an opioid, may induce opposite effects, these results are not paradoxical if they are analyzed from an adaptive viewpoint. SIA triggered by endogenous opioids is considered in naive rats as an adaptive and beneficial strategy to facilitate appropriate defensive responses in an initial threatening situation. However, the opposite response SIH might also be considered as an adaptive strategy for facilitating recuperative behaviors after stress in pain and opioid-experienced animals. Indeed, the expression of latent pain hypersensitivity as it was observed in this rat study might be a component of anticipatory recuperative behavior allowing the animal to focus its attention on the pathological consequences of threatening and subsequent tissue injuries. Our model of pain vulnerability could be an interesting experimental model to study the transition from acute to chronic pain, especially long-lasting pain resistant to opioids. By using different approaches developed in this experimental animal study, the role of such latent pain sensitization in individual pain vulnerability has to be evaluated in humans.

\section{ACKNOWLEDGEMENTS}

This work is supported by Universite Victor Segalen Bordeaux 2, Université Bordeaux 1, the Ministère de l'Education nationale, de l'Enseignement supérieur et de la Recherche and the Conseil Régional d'Aquitaine. CR is a recipient of a doctoral fellowship from the Ministère de l'Education nationale, de l'Enseignement supérieur et de la Recherche. The study was performed at the Laboratoire 'Homeostasie-Allostasie-Pathologie' EA3666, Université Victor Ségalen Bordeaux 2.

\section{REFERENCES}

Akil H, Madden JH, Patrick RL, Barchas JD (1976). Stress-induced increase in endogenous opiate peptides: concurrent analgesia and its partial reversal by naloxone. In: Kosterlitz HW (ed). Opiates and Endogenous Opioid Peptides. North-Holland: Amsterdam. pp 63-70.

Angst MS, Clark JD (2006). Opioid-induced hyperalgesia: a qualitative systematic review. Anesthesiology 104: 570-587.

Angst MS, Koppert W, Pahl I, Clark DJ, Schmelz M (2003). Shortterm infusion of the mu-opioid agonist remifentanil in humans causes hyperalgesia during withdrawal. Pain 106: 49-57.

Bespalov AY, Zvartau EE, Beardsley PM (2001). Opioid-NMDA receptor interactions may clarify conditioned (associative) components of opioid analgesic tolerance. Neurosci Biobehav Rev 25: 343-353.

Bradesi S, Schwetz I, Ennes HS, Lamy CM, Ohning G, Fanselow M et al (2005). Repeated exposure to water avoidance stress in rats: a new model for sustained visceral hyperalgesia. Am J Physiol Gastrointest Liver Physiol 289: G42-G53.

Célèrier E, Laulin JP, Corcuff JB, Le Moal M, Simonnet G (2001). Progressive enhancement of delayed hyperalgesia induced by repeated heroin administration: a sensitization process. J Neurosci 21: 4074-4080.

Célèrier E, Rivat C, Jun Y, Laulin JP, Larcher A, Reynier P et al (2000). Long-lasting hyperalgesia induced by fentanyl in rats: preventive effect of ketamine. Anesthesiology 92: 465-472.

Chen L, Huang LY (1991). Sustained potentiation of NMDA receptor-mediated glutamate responses through activation of protein kinase C by a mu opioid. Neuron 7: 319-326.

Chen L, Huang LY (1992). Protein kinase C reduces $\mathrm{Mg}^{2+}$ block of NMDA-receptor channels as a mechanism of modulation. Nature 356: 521-523.

Chia YT, Liu K, Wang JJ, Kuo MC, Ho ST (1999). Intraoperative high dose fentanyl induces postoperative fentanyl tolerance. Can J Anaesth 46: 872-877.

Crain SM, Shen KF (1990). Opioids can evoke direct receptormediated excitatory effects on sensory neurons. Trends Pharmacol Sci 11: 77-81.

Crain SM, Shen KF (1998). Modulation of opioid analgesia, tolerance and dependence by Gs-coupled, GM1 gangliosideregulated opioid receptor functions. Trends Pharmacol Sci 19: 358-365.

da Silva Torres IL, Cucco SN, Bassani M, Duarte MS, Silveira PP, Vasconcellos AP et al (2003). Long-lasting delayed hyperalgesia after chronic restraint stress in rats-effect of morphine administration. Neurosci Res 45: 277-283.

De Kock M, Lavand'homme P, Waterloos H (2001). Balanced analgesia' in the perioperative period: is there a place for ketamine? Pain 92: 373-380.

Galeotti N, Stefano GB, Guarna M, Bianchi E, Ghelardini C (2006). Signaling pathway of morphine induced acute thermal hyperalgesia in mice. Pain 123: 294-305.

Gameiro GH, Gameiro PH, Andrade Ada S, Pereira LF, Arthuri MT, Marcondes FK et al (2006). Nociception- and anxiety-like behavior in rats submitted to different periods of restraint stress. Physiol Behav 87: 643-649.

Guignard B, Bossard AE, Coste C, Sessler DI, Lebrault C, Alfonsi P et al (2000). Acute opioid tolerance: intraoperative remifentanil increases postoperative pain and morphine requirement. Anesthesiology 93: 409-417.

Guignard B, Coste C, Costes H, Sessler DI, Lebrault C, Morris W et al (2002). Supplementing desflurane-remifentanil anesthesia with small-dose ketamine reduces perioperative opioid analgesic requirements. Anesth Analg 95: 103-108, table of contents.

Hirbec H, Teilhac J, Kamenka J, Privat A, Vignon J (2000). Binding properties of [3H]gacyclidine(cis(pip/me)-1-[1-(2-thienyl)-2methylcyclohexyl]piperidine) enantiomers in the rat central nervous system. Brain Res 859: 177-192.

Hirota K, Lambert DG (1996). Ketamine: its mechanism(s) of action and unusual clinical uses (editorial). Br J Anaesth 77: 441-444. 
Hoizey G, Kaltenbach ML, Dukic S, Lamiable D, Millart H, D'Arbigny $\mathrm{P}$ et al (2001). Pharmacokinetics of gacyclidine enantiomers in plasma and spinal cord after single enantiomer administration in rats. Int J Pharm 229: 147-153.

Kayser V, Guilbaud G (1990). Differential effects of various doses of morphine and naloxone on two nociceptive test thresholds in arthritic and normal rats. Pain 41: 353-363.

Khasar SG, Green PG, Levine JD (2005). Repeated sound stress enhances inflammatory pain in the rat. Pain 116: 79-86.

Kim DH, Fields HL, Barbaro NM (1990). Morphine analgesia and acute physical dependence: rapid onset of two opposing, doserelated processes. Brain Res 516: 37-40.

Laulin JP, Larcher A, Célèrier E, Le Moal M, Simonnet G (1998). Long-lasting increased pain sensitivity in rat following exposure to heroin for the first time. Eur J Neurosci 10: 782-785.

Laulin JP, Maurette P, Corcuff JB, Rivat C, Chauvin M, Simonnet G (2002). The role of ketamine in preventing fentanyl-induced hyperalgesia and subsequent acute morphine tolerance. Anesth Analg 94: 1263-1269.

Lewis JW, Cannon JT, Liebeskind JC (1980). Opioid and nonopioid mechanisms of stress analgesia. Science 208: 623-625.

Mao J (2002). Opioid-induced abnormal pain sensitivity: implications in clinical opioid therapy. Pain 100: 213-217.

Mao J, Price DD, Mayer DJ (1994). Thermal hyperalgesia in association with the development of morphine tolerance in rats: roles of excitatory amino acid receptors and protein kinase $\mathrm{C}$. J Neurosci 14: 2301-2312.

Mao J, Sung B, Ji RR, Lim G (2002). Chronic morphine induces downregulation of spinal glutamate transporters: implications in morphine tolerance and abnormal pain sensitivity. J Neurosci 22: 8312-8323.

Martin WR, Gilbert PE, Jasinski DR, Martin CD (1987). An analysis of naltrexone precipitated abstinence in morphine-dependent chronic spinal dogs. J Pharmacol Exp Ther 240: 565-570.

North RA, Williams JT (1976). Enkephalin inhibits firing of myenteric neurones. Nature 264: 460-461.

Ossipov MH, Lai J, Vanderah TW, Porreca F (2003). Induction of pain facilitation by sustained opioid exposure: relationship to opioid antinociceptive tolerance. Life Sci 73: 783-800.

Perkins FM, Kehlet H (2000). Chronic pain as an outcome of surgery. A review of predictive factors. Anesthesiology 93: 1123-1133.

Richebe P, Rivat C, Laulin JP, Maurette P, Simonnet G (2005). Ketamine improves the management of exaggerated postoperative pain observed in perioperative fentanyl-treated rats. Anesthesiology 102: 421-428.
Rivat C, Laulin JP, Corcuff JB, Celerier E, Pain L, Simonnet G (2002). Fentanyl enhancement of carrageenan-induced longlasting hyperalgesia in rats: prevention by the $N$-methyl-Daspartate receptor antagonist ketamine. Anesthesiology 96: 381-391.

Satoh M, Kuraishi Y, Kawamura M (1992). Effects of intrathecal antibodies to substance $\mathrm{P}$, calcitonin gene-related peptide and galanin on repeated cold stress-induced hyperalgesia: comparison with carrageenan-induced hyperalgesia. Pain 49: 273-278.

Simonin F, Schmitt M, Laulin JP, Laboureyras E, Jhamandas JH, Mactavish D et al (2006). RF9, a potent and selective neuropeptide FF receptor antagonist, prevents opioid-induced tolerance associated with hyperalgesia. Proc Natl Acad Sci USA 103: $466-471$.

Simonnet G, Rivat C (2003). Opioid-induced hyperalgesia: abnormal or normal pain? Neuroreport 14: 1-7.

Stubhaug A, Breivik H (1997). Long-term treatment of chronic neuropathic pain with the NMDA ( $N$-methyl-D-aspartate) receptor antagonist ketamine (editorial; comment). Acta Anaesthesiol Scand 41: 329-331.

Suarez-Roca H, Silva JA, Arcaya JL, Quintero L, Maixner W, Pinerua-Shuhaibar L (2006). Role of mu-opioid and NMDA receptors in the development and maintenance of repeated swim stress-induced thermal hyperalgesia. Behav Brain Res 167: 205-211.

Vanderah TW, Gardell LR, Burgess SE, Ibrahim M, Dogrul A, Zhong CM et al (2000). Dynorphin promotes abnormal pain and spinal opioid antinociceptive tolerance. J Neurosci 20 7074-7079.

Vidal C, Jacob J (1982). Hyperalgesia induced by non-noxious stress in the rat. Neurosci Lett 32: 75-80.

Wilder-Smith OH, Arendt-Nielsen L (2006). Postoperative hyperalgesia: its clinical importance and relevance. Anesthesiology 104: 601-607.

Woolf CJ, Salter MW (2000). Neuronal plasticity: increasing the gain in pain. Science 288: 1765-1769.

Xie JY, Herman DS, Stiller CO, Gardell LR, Ossipov MH, Lai J et al (2005). Cholecystokinin in the rostral ventromedial medulla mediates opioid-induced hyperalgesia and antinociceptive tolerance. J Neurosci 25: 409-416.

Zarate E, Sa Rego MM, White PF, Duffy L, Shearer VE, Griffin JD et al (1999). Comparison of adenosine and remifentanil infusions as adjuvants to desflurane anesthesia. Anesthesiology 90: $956-963$. 